https://helda.helsinki.fi

\title{
The use of Twitter for innovation in business markets
}

\section{Cripps, Helen}

2020-08-03

Cripps , H , Singh , A , Mejtoft , T \& Salo , J 2020 , ' The use of Twitter for innovation in business markets ' , Marketing Intelligence \& Planning , vol. 38 , no. 5 , pp. 587-601 . https://doi.org/10.1108/MIP-06

http://hdl.handle.net/10138/317717

https://doi.org/10.1108/MIP-06-2019-0349

cc_by

publishedVersion

Downloaded from Helda, University of Helsinki institutional repository.

This is an electronic reprint of the original article.

This reprint may differ from the original in pagination and typographic detail.

Please cite the original version. 


\title{
The use of Twitter for innovation in business markets
}

\author{
Helen Cripps \\ Edith Cowan University - Joondalup Campus, Joondalup, Australia \\ Abhay Singh \\ Macquarie University, Sydney, Australia and \\ Edith Cowan University, Joondalup, Australia \\ Thomas Mejtoft \\ Umea University, Umea, Sweden, and \\ Jari Salo \\ Faculty of Agriculture and Forestry, University of Helsinki, Helsinki, Finland
}

Use of Twitter in business

\begin{abstract}
Purpose - The purpose of this research is to investigate the use of Twitter in business as a medium for knowledge sharing and to crowdsource information to support innovation and enhance business relationships in the context of business-to-business (B2B) marketing.

Design/methodology/approach - This study uses a combination of methodologies for gathering data in 52 face-to-face interviews across five countries and the downloaded posts from each of the interviewees' Twitter accounts. The tweets were analysed using structural topic modelling (STM), and then compared to the interview data. This method enabled triangulation between stated use of Twitter and respondent's actual tweets.

Findings - The research confirmed that individuals used Twitter as a source of information, ideas, promotion and innovation within their industry. Twitter facilitates building relevant business relationships through the exchange of new, expert and high-quality information within like-minded communities in real time, between companies and with their suppliers, customers and also their peers.

Research limitations/implications - As this study covered five countries, further comparative research on the use of Twitter in the B2B context is called for. Further investigation of the formalisation of social media strategies and return on investment for social media marketing efforts is also warranted.

Practical implications - This research highlights the business relationship building capacity of Twitter as it enables customer and peer conversations that eventually support the development of product and service innovations. Twitter has the capacity for marketers to inform and engage customers and peers in their networks on wider topics thereby building the brand of the individual users and their companies simultaneously.

Originality/value - This study focuses on interactions at the individual level illustrating that Twitter is used for both customer and peer interactions that can lead to the sourcing of ideas, knowledge and ultimately innovation. The study is novel in its methodological approach of combining structured interviews and text mining that found the topics of the interviewees' tweets aligned with their interview responses.
\end{abstract}

Keywords Social media, Innovation, Twitter, Crowdsourcing, Topic modelling, Business to business marketing

Paper type Research paper

\section{Introduction}

Innovation is central to the creation of competitive advantage of a firm by contributing to its market orientation, brand perception and overall success in a highly competitive marketplace (Amyx et al., 2016; Zameer et al., 2019). The involvement of customers in the innovation process

(C) Helen Cripps, Abhay Singh, Thomas Mejtoft and Jari Salo. Published by Emerald Publishing Limited. This article is published under the Creative Commons Attribution (CC BY 4.0) licence. Anyone may reproduce, distribute, translate and create derivative works of this article (for both commercial and noncommercial purposes), subject to full attribution to the original publication and authors. The full terms of this licence may be seen at: http://creativecommons.org/licences/by/4.0/legalcode

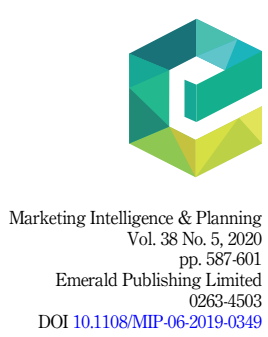

Received 2 November 2018 Revised 19 September 2019 22 November 2019 12 December 2019 Accepted 1 January 2020 
has been discussed from the perspectives of service innovation (Lusch and Nambisan, 2015), customer co-creation (D'Andrea et al, 2019) and crowdsourcing of innovation in both the business-to-consumer (B2C) and business-to-business (B2B) contexts (Salo, 2017). Consequently, the exchange of knowledge between the customer and the firm can assist in creating innovation and in building customer value (Daghfous et al, 2013).

The Internet has created a paradigm shift in communications over the last 25 years transforming interactions by enabling communication between dispersed and decentralised individuals and entities (Kaplan and Haenlein, 2010; Wang et al., 2017). The two-way nature of Internet-based communication through social media makes it an effective and dynamic medium for B2C exchanges (Leonardi et al., 2013; Tarnovskaya and Biedenbach, 2018). Social media platforms are now being used by companies to access knowledge to crowdsource ideas, information and resources from employees and customers in all corners of the globe, which is proving to be a powerful tool to create innovations (Estellés-Arolas and GonzálezLadrón-de-Guevara, 2012; Jussila et al., 2015). This online exchange has the potential to generate increased collaboration within a company, creating a culture of open innovation (Scupola and Nicolajsen, 2013).

Innovation is central to gaining and sustaining competitive advantage and platforms, such as Twitter can be a source of new knowledge and ideas. The objective of this research is to investigate how Twitter, a social media platform, is used by small and medium-sized firms, as a medium for knowledge sharing and innovation in business markets, and how Twitter is being used to support innovation within and between companies.

\subsection{Research questions}

The following research questions are addressed in the research:

$R Q 1$. How is Twitter used as a tool for marketing in B2B markets?

RQ2. Can Twitter be used as a tool for crowdsourcing, knowledge sharing and innovation in B2B markets?

RQ3. Can text-mining technique of topic modelling relate interviewees' responses to their Twitter use?

\section{Theoretical framework}

In the globalised economy, innovation is now a major reason for the success and failure of many products and industries in the era of digitalisation (e.g. Bower and Christensen, 1995). Innovation is about creating something completely new or the recombination of old elements into something new (Schumpeter, 1934; Sundbo, 1997). Innovation can be described as either open or closed, depending on the source of the ideas. The concept of open innovation (Chesbrough, 2003) and other forms of user involvement in innovation processes (von Hippel, 1986) became increasingly popular since the beginning of the 2000s. Today, innovation, and especially open innovation, has been deemed an important component to assist firms to make quick moves to gain and sustain competitive advantages in the increasingly aggressive and fast-paced competitive environment (Zameer et al.,2019). Crowdsourcing of innovation as a way of increasing users' involvement in the innovation process has become increasingly discussed in research (Salo, 2017). Simula and Ahola (2014) categorise four innovation crowdsourcing configurations, out of which two, community crowdsourcing and open crowdsourcing give the firm both a higher control and a high degree of openness in their crowdsourcing activities, enabling the co-creation of products and services with current or potential customers, particularly in the B2C context (D’Andrea et al., 2019). 


\subsection{Social media's role in knowledge and innovation}

The two-way nature of social media platforms makes them effective channels for customer engagement by enabling businesses to listen, respond and engage in discussion with customers (Tsimonis and Dimitriadis, 2014). These platforms have created new opportunities for companies to crowdsource innovation as 'the knowledge of creativity was once locked up in social structures and codified volumes ... it is now widely distributed, accessible throughout the planet' (Sapsed and Tschang, 2014, p. 140). Social media allows for creation and exchange of user-generated content across a vast range of available platforms, stretching from content-sharing sites (e.g. YouTube) to full social networking sites (e.g. Facebook) (Kaplan and Haenlein, 2010). The information exchange enabled by social media provides an opportunity for businesses to learn from users, competitors and industry as a whole, thereby creating opportunities for the support of innovation in both social and commercial contexts (Curran et al., 2011; Pérez-González et al., 2017). The unprecedented information visibility in social media has changed the ways in which people source and manage information (Leonardi, 2014), providing a source of competitive intelligence for the corporate innovation process (Floresa et al., 2015; Shao et al., 2015).

The use of micro blogs, such as Twitter, has become important for both individuals and organisations to broadcast and discuss opinions in real-time (Zanini et al., 2019). Twitter's use in industrial markets is a more recent phenomenon, with firms using Twitter to manage interactions with customers (Andzulis et al., 2012; Sashittal and Jassawalla, 2019). Twitter's conversational nature has prompted calls for research into the use of micro blogs in the aspect of innovation (Dobele et al., 2015). Simula et al. (2013) found that firms involved in business markets displayed a level of hesitancy to adopt and utilise social media tools. Security risks along with misinterpretation of information were mentioned as reasons for this hesitancy (Mehmet and Clarke, 2016). Since crowdsourcing is always based on some kind of collaboration, participation and the use of social media tools when crowdsourcing information are linked to the commitment-trust theory (Morgan and Hunt, 1994). According to Swani et al. (2014), marketers use Twitter to message differently between the industrial and consumer contexts, with B2B companies tending to use more emotional than functional appeals in their tweets and avoided the 'hard sell' (Swani et al., 2014).

The use of social media in knowledge exchange and innovation has been widely researched in the $\mathrm{B} 2 \mathrm{C}$ context, but there has been little research about its use in the $\mathrm{B} 2 \mathrm{~B}$ context, which differs from B2C, particularly in the area of small and medium enterprises that can experience a power asymmetry when building business relationships with larger firms (Inakova et al., 2019). Additionally, Salo et al. (2013) highlight the need for research into the role that specific social media tools played in business markets. Research investigating how companies use social media has risen in prominence in the marketing literature during the last ten years. Recent reviews of research (Huotari et al., 2015; Karjaluoto et al., 2015: Salo, 2017) conclude that previous research has focused on the sales and tactical use of social media, rather than on the strategic use for knowledge exchange and innovation. There are attempts to describe how social media can be used in all phases of innovation (He and Wang, 2016), but there are still limited understandings of the effectiveness of using social media in innovation processes (Chen et al., 2012).

\section{Methodology}

To address the lack of research in the use of social media as a source of knowledge for innovation and due to the research questions' contemporary, real-life and complex character, this study is grounded in a mix of methods (e.g. Stake, 2005). Previous research has pointed towards the need to explore the use of social media using qualitative methods for further insights into the real intentions (Tarnovskaya and Biedenbach, 2018). The 40 social media 
business markets articles reviewed by Salo (2017) and Huotari et al. (2015) used either interviews or surveys, and none used the combination of interviews and topic modelling of the respondents' tweets. To more accurately relate perceptions to actual behaviour, this study is based on a combination of face-to-face interviews and downloaded tweets from each of the interviewees' Twitter accounts, which were further analysed using structural topic modelling (STM).

\subsection{Interviews}

Previous research has used the text mining of companies Twitter feeds as a data source (He and Wang, 2016; Mehmet and Clarke, 2016; Swani et al., 2014), but very little research has been published investigating the motivations for the use of Twitter in the B2B context. The interview questions were based on the UTAUT scale with alterations to fit with the context of Twitter usage (Venkatesh et al., 2016). The 52 interviews were carried out in the period August-October 2015 across England (12), Germany (11), Sweden (8), Finland (13) and Norway (8). All the interviews were conducted face-to-face in English, using structured interviews (Fontana and Frey, 2005), complemented with open-ended questions. The open-ended questions were coded by identifying themes across the responses by the interviewer, and these were then reviewed by two of the other researchers to assist with validating the coding of the responses and themes. The interviewees' age ranged between 21 and 60 years of age, with 35 per cent being between 31 and 40 years of age, and 77 per cent were male. Marketing was the primary role of the interviewees ( 40 per cent), 21 per cent were founders, 15 per cent CEOs and 11 per cent involved in IT-related activities. Furthermore, 75 per cent had worked in their current role for five years or less. The interviewees worked for organisations that ranged from consultancy or micro businesses employing less than 10 people, to large multinational businesses employing over 2,500 people. In all, 75 per cent of the companies had 100 or less employees, and 57 per cent had 25 or less employees. These were predominantly IT-related start-ups.

\subsection{Structural topic modelling}

Topic models are probabilistic statistical text mining algorithms for discovering the underlying meaningful text organisation of a document to uncover the main themes in an unstructured collection of text. Hoffman (2001) proposed one of the first such probabilistic topic modelling algorithms, which was then succeeded by latent Dirichlet allocation (LDA) by Blei et al. (2003). Blei et al. (2003) proposed LDA as an unsupervised approach that assumes a document comprises of multiple topics.

Topics are defined as a distribution over a set vocabulary of terms (words). Topic modelling algorithm assumes that a certain number of topics $(k)$ are present in a collection of (n) documents in different proportions. Each term (word) originates from one of the topics, which is identified from the per-document distribution over topics. LDA defines a Dirichlet distribution to identify these topics for each document. STM method (Roberts et al., 2016) is an extension of probabilistic topic models such as LDA. Although based on similar principles, compared to LDA, STM method has some significant differences. It can allow for correlated topic modelling, is modelled with each document having its own distribution over topics based on covariate variable(s) and the words per topic can also vary by covariate(s).

The text mining analysis in this study uses STM to search for possible topics in a sample of tweets posted by the interviewees. The STM method is particularly useful in this analysis, as it allows for inclusion of metadata in the text corpus. This allows STM to model topical prevalence, specified as simple generalised linear model on a number of document-level covariates. The STM method has been gaining popularity in academic research to generate topics from various sources of data like international newspapers, open-ended interview responses, online class forums and Twitter data (Lucas et al., 2015; Roberts et al., 2016). 
The estimation methodology for STM will not be discussed here for the sake of brevity, and the discussion is kept limited to the application of the model and major results.

All the interviewees were asked to estimate the number of employees in their firm and the frequency and purpose of their use of Twitter, which has been used to further filter the text corpus for the STM analysis. The text corpus used for the topic modelling exercise consists of tweets posted by a group of interviewees from companies with less than 100 employees. These companies are categorised as small or medium-scale enterprises (SME)[1], which are further divided into SMEs using Twitter for innovation and crowdsourcing, at least once a month and less based on their responses during the interview. The final sample includes 38 companies, with 10 having reported using Twitter at least once a month for innovation and crowdsourcing and 28 using it less than once a month. This binary classification for SMEs is used as the covariate in the STM analysis to check if the topic prevalence differs in these two SME classes.

The tweet database included the most recent 500 tweets or less (depending on the number of available tweets) per user, which were downloaded subsequent to the interviews being conducted. The data sample contains 15,054 multilingual tweets from 38 Twitter handles. As the tweets are posted in various languages (e.g. Finnish, German, Swedish), they are first translated to English using the Google Translate API (via Google Sheets)[2] for the analysis. Although it wasn't possible to double-check all the translations, translations from familiar languages, such as Swedish, Finnish and German, were randomly checked. For the topic modelling exercise, the dataset is pre-processed to remove non-character text, html code and common English stop words. The dataset is further stemmed to reduce words to their root form before conducting the analysis. Additionally, the words appearing in less than 10 tweets are dropped from the dataset, which adjusts the vocabulary and the number of tweets resulting in 14,704 tweets and 1,768 words in the vocabulary.

The STM (Roberts et al., 2014a) package in $R$ was used to conduct the topic modelling analysis. The analysis of the interviewees' Twitter streams used the 'Spectral' initialisation method that is based on the method of moments and achieves globally consistent results under reasonable conditions (Roberts $e$ t al., 2014c and 2014b). The analysis used STM with 20 topics fit to the data. An analysis of topic semantic coherence and exclusivity (Roberts et al., 2014c) conducted for number of topics ranging from 20 to 40 revealed 20 as a conservative but satisfactory number of topics to explore in the study.

\section{Results and discussion}

\subsection{Results from the interviews}

While 85 per cent of interviewees checked their Twitter account daily, only 46 per cent of interviewees tweeted daily. The interviewees used Twitter primarily as a channel for communication and information gathering (Hänninen and Karjaluoto, 2017). The interviewees did not believe that they had to use Twitter to compete in their industry, and generally they were one of the few Twitter users in their firm (Keinänen and Kuivalainen, 2015).

When deciding to follow someone on Twitter, being knowledgeable and being influential were considered to be important characteristics (Hänninen and Karjaluoto, 2017). Interviewees cited other factors in their decision to follow someone, including "level of innovative thought', 'new inspiration and ideas' and 'learn from others, reciprocation of interests' showing that using Twitter for sourcing innovative ideas is fairly common. The level of authenticity and integrity of the accounts the respondent followed was considered important, as the tweets of the accounts that the interviewees followed appear on their own Twitter feed (Valos et al., 2016). If the content was inappropriate, this reflected poorly on the account owner and the firm for which they worked. Similarly, the main reasons the interviewees unfollowed someone on Twitter were that the information they provided was no longer of interest, trustworthy or of sufficient quality.
Use of Twitter in business 
MIP

38,5

592

The benefits of using Twitter included the ability to build trust, provided quality information distribution and exchange and linked or collaborated with others in the industry which is consistent with the commitment-trust theory (Morgan and Hunt, 1994) and similar to Quinton and Wilson's (2016) findings in relation to LinkedIn. Furthermore, Twitter enabled a 'quick way to distribute information', was beneficial when 'gathering business intelligence', 'create a community - our company started with a tweet to the world', 'crowdsourced way of finding interesting stuff' and was a way to 'identify trends, what's next'. The risks of using Twitter related to the loss of control of the conversation, being misunderstood and raising the negativity of others (Mejtoft, 2014; Mehmet and Clarke, 2016; Valos et al., 2016). Only 48 per cent of the interviewees had a formal written social media policy, 17 per cent had an informal policy and 35 per cent said they had no policy at all. This finding is consistent with Iankova et al. (2019), who found a lack of formal strategies in B2B firms. The interviewees were asked to describe the types of guidelines they applied when using Twitter; responses included being conversational, informative, providing quality content and the use of common sense when posting information.

The interviewees agreed (92 per cent) that 'using Twitter enhances your creditability', and 75 per cent agreed that using Twitter makes it easier to gather information. This is aligned with the concepts of social enhancement (Yavuz and Toker, 2014) and personal branding (Khedher, 2014; Ngai et al., 2015) in the B2C context, not the B2B context.

These results indicate that Twitter is a source of credible knowledge, information and innovative ideas and are consistent with the previous research, such as of Kaplan and Haenlein (2010). The instantaneousness of the Twitter feed as conduit for awareness and information exchange supports the findings of Leek et al. (2019). These results were the impetus for the investigation of the content of the interviewees' Twitter feeds using STM analysis.

4.1.2 Results from STM analysis. The 20 topics derived from the STM analysis of the Twitter streams are displayed in Figure 1, which provides a list of top topics according to their expected proportion in the tweets posted by the interviewees. The topics generated in the analysis are formed of words associated with them. Figure 1 shows top 10 words (according to their probability of occurrence) per topic, which are used to identify the

\section{Top Topics}

Figure 1.

Topics sorted according to their expected occurrence

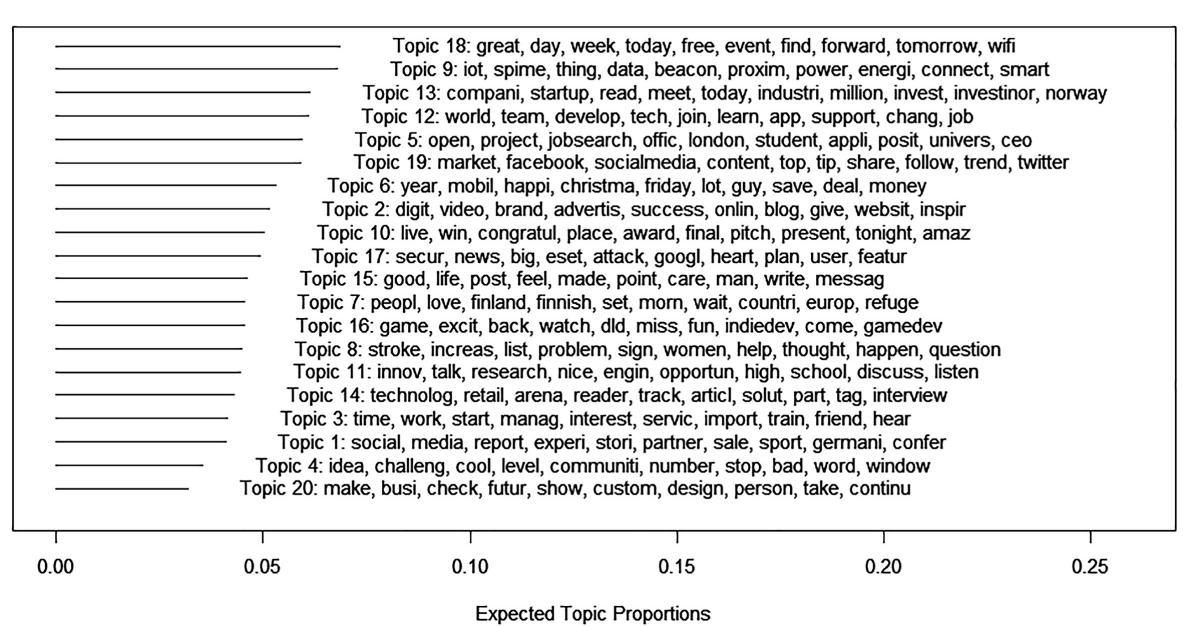


generalised topics. For example, Topic 18 has the highest proportion in the data has words like 'day', 'week' and 'today', which are associated with describing daily activities or used for posting updates on Twitter.

On closer inspection of these topics, it is observed that some of the topics have common words. For example, Topic 1 and Topic 19 have words like 'social', 'media' and 'socialmedia'. This indicates that there can be some correlation between these topics making them related to each other, and hence a further analysis of this likely correlation is conducted to group the topics together.

STM analysis has been used further to find these correlated related topics that are likely to be discussed within a document. This additional correlation analysis aims to summarise the topics such that the related topics can be grouped into one broader topic and the rest can be treated as individual topics for further analysis and discussion. Table I provides a list of these topics, which have been assigned a group according to the degree of correlation[3] among the topics and generalised topic label based on the top 10 words in each. These topics will now be discussed in relation to their context.

Analysing Figure 1 and Table I, it can be observed that Topic 18, which is under the generalised group (group 1) of 'General Social Media', is the most common topic among the tweets posted by the interview participants. Topic 18 has words like 'great', 'day', 'today' and 'event' which are usually used for day-to-day social media interactions, in this case updates posted in tweets by the users. Another highly ranked topic in this first group is Topic 12 , which is formed by the words used to describe technological collaboration. Overall, this group has topics related to general social media use, online marketing, technological development and collaboration and online promotion. This is an encouraging result as it verifies the expectation that the Twitter users who are from SMEs and are always looking to expand their business and be a part of today's technological advancements will post tweets about these topics.

Table I, furthermore, contains groups 2 and 3, with two topics each. In particular, Topic 5 and Topic 11 are correlated and comprise of words like 'project', 'student', 'appli' (for application), 'research' and 'opportune' (for opportunity). These two topics in general talk about open innovation and learning. Hence, the STM method verifies that in the tweet sample, users are using Twitter for innovation, which involves gathering ideas and academic learning.

Table I shows seven topics, viz., Topics 4, 7, 9,10,13, 14 and 16 , which have correlation of less than 0.05 with other topics and are identified as individual topics. Out of these seven topics, Topic 9, which is the second-ranked topic (Figure 1), talks about Internet of Things (IoT) and big data. This topic has interesting words like, 'iot'(internet of things), 'spime' (for futuristic object), 'data' and 'energi', which are relevant to the IoT advancement of today and 'everything data' in the innovation landscape for SMEs. Similarly, various other topics are identified and labelled from the list of topics. The analysis using STM with correlation summarises the topics in 10 broader topics, which capture the overall theme in the tweets data. These themes reflect upon the way the interviewees use Twitter as a social media channel. It can be inferred that the tweets posted by the interviewees are not only to update their followers about their daily routine or happenings but are heavily focussed on current technological advancements and start-up scene.

One of the advantages of using STM is that it enables the exploration of the relationship between the text and metadata. This allows the modelling of the relationship between generated topics and class of the Twitter users in the sample dataset. The mean difference for all 20 topics was compared for two different groups. The results show (1) SMEs that report the use of Twitter for innovation activities such as crowdsourcing of ideas or information less than once a month and (2) SMEs that use Twitter for the same at least once a month (SME_Inov). This further analysis based on the SME factors shows (Figure 2) that various topics, including Topic 9 (IoT and big data) and Topic 14 (Technology in Retail), occur more frequently among these interviewees in the second category of interviewees who use Twitter
Use of Twitter in business 
MIP

38,5

594

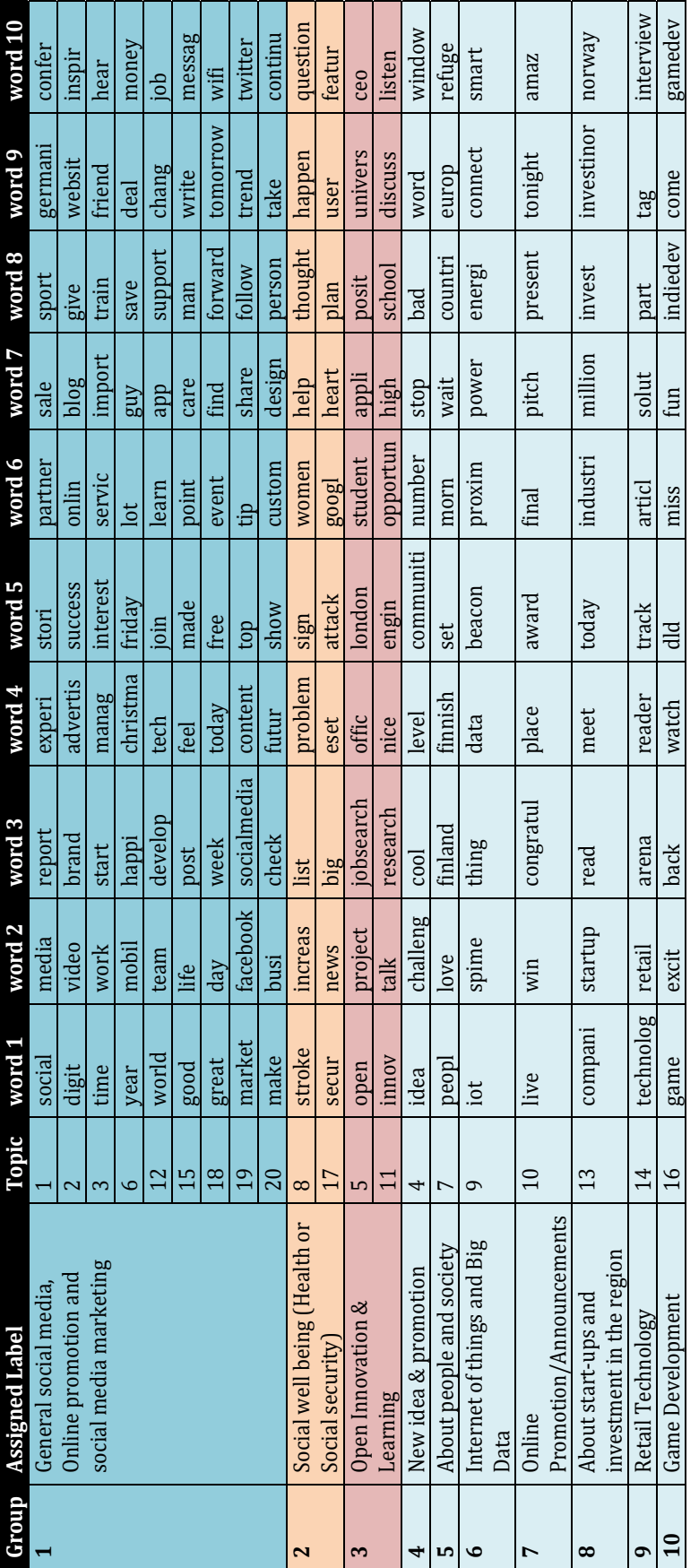

Table I.

Labelled topics with top 10 words in each

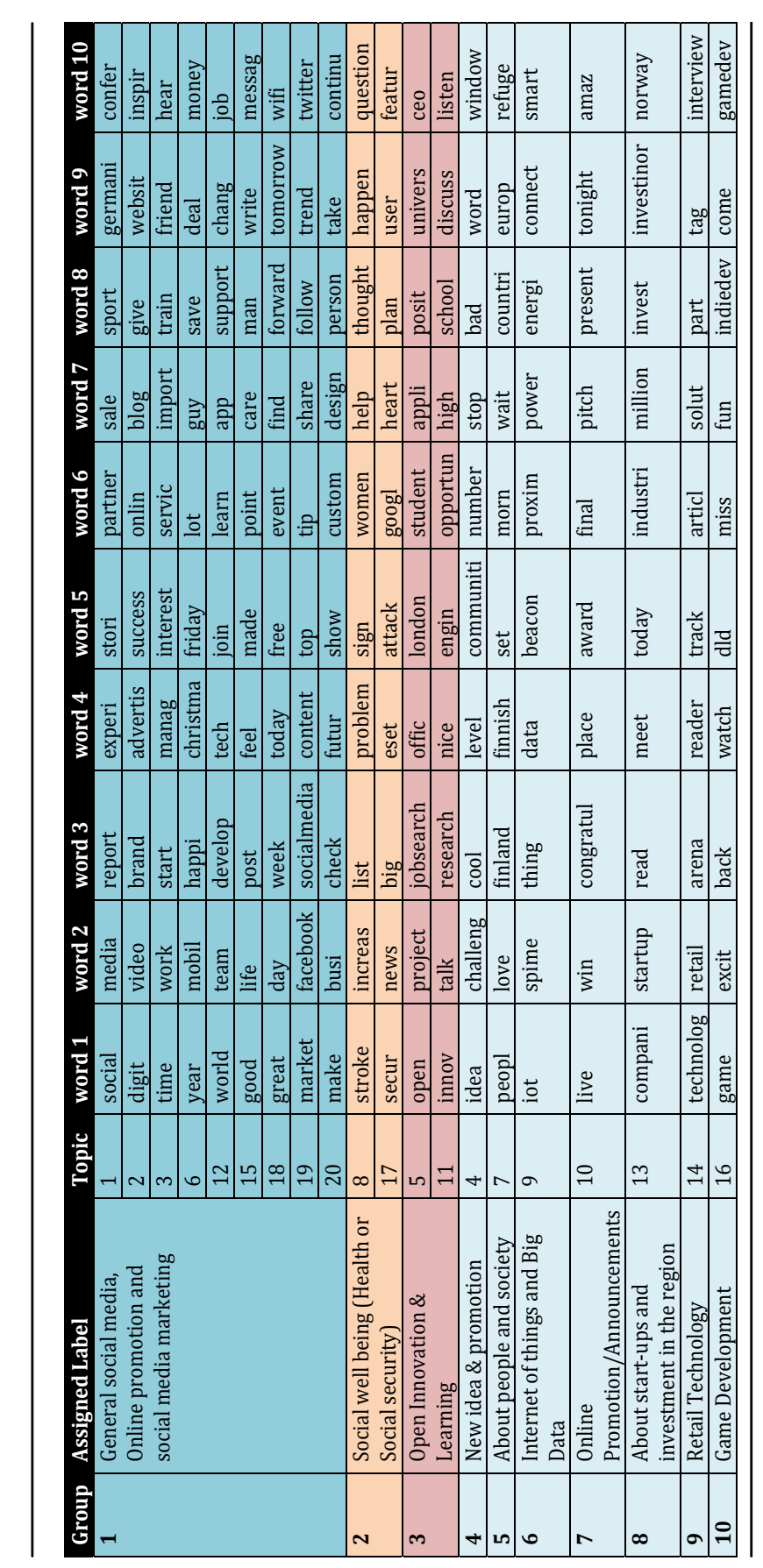


SME vs. SME_INOV

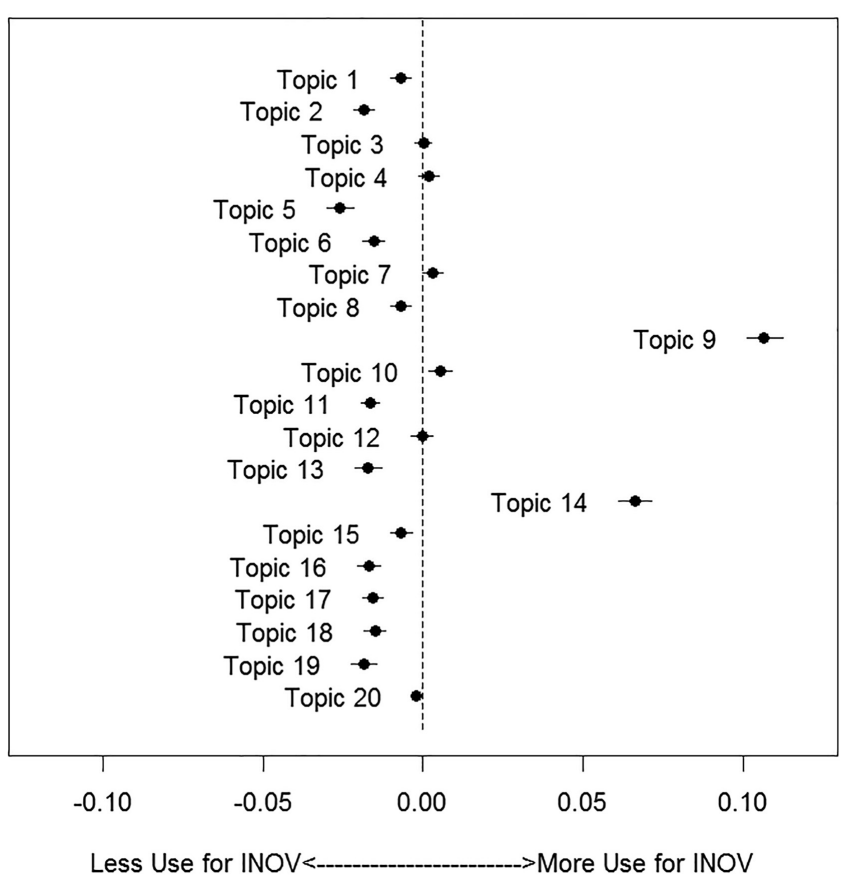

Use of Twitter in business

595

for crowdsourcing, innovation and gathering ideas. These are insightful results, as Topics 4, 7 and 10 about new ideas, promotion and society are also more frequently used by the SMEs using Twitter for innovation.

These results indicate that the SMEs in our sample are in fact utilising Twitter as a social media channel for open innovation and crowdsourcing, information and feedback. Overall, the topics related to today's advancements in technology, including, IoT, big data, the retail sector and new ideas, are among the topics more frequently talked about by SMEs identifying themselves as the ones using Twitter for innovation and crowdsourcing at least once a month.

The STM analysis provides some insightful results in terms of not only the words generated for different topics but also the different topical prevalence depending on the purpose and frequency of use of Twitter. Overall, it can be concluded that the results generated using modern text mining method of STM verify the results from the interviews. The analysis successfully identifies words utilised by Twitter users in our sample, which they frequently use to discuss innovation around technological advancements in the European region. The identified topics also show how the technologically advanced fields of IoT and big data are popular among SMEs looking for innovation. Investigating other covariates like industry sector can develop this initial analysis further or the number of followers to create a lexicon with frequently used words around innovation, crowdsourcing, gathering ideas and social media marketing.

\section{Theoretical contribution and managerial implications}

\subsection{Theoretical contribution}

The results from both data sources supported $R Q 1$, that Twitter is used as a tool in B2B markets, providing companies with a powerful channel to access information, knowledge and 
build relationships from which to develop innovations and sustain competitiveness (Swani et al., 2014; Estellés-Arolas and González-Ladrón-de-Guevara, 2012). Innovation is central to a firm's competitive advantage, and previous research has shown that social media channels have a role to play in the development and support of this innovation (Floresa et al., 2015; Shao et al., 2015). The results strengthen previous findings (Floresa et al., 2015; Leek et al., 2019) that social media channels such as Twitter can be used as a source of information, ideas and innovation through crowdsourcing.

The results supported $R Q 2$ showing that Twitter can be used as a tool for crowdsourcing, knowledge sharing and innovation in B2B markets. These findings highlight the value of Twitter as a platform for the exchange of new, expert and high-quality information within like-minded communities (Leonardi, 2014; Pérez-González et al., 2017). The immediate nature of the Twitter feed enables collaboration in real time between companies and their suppliers, customers and peers (Edosomwan et al., 2011). The importance of peer-to-peer discussions or communications and access to experts and thought leaders for B2B companies was evident from the interview findings (Leonardi et al., 2013; Poon et al., 2012). The peer-to-peer interaction enabled by Twitter was also seen as a means of improving personal credibility in an area more closely associated with B2C interactions (Khedher, 2014; Ngai et al., 2015; Tarnovskaya; Biedenbach, 2018).

For $R Q 3$, the research found that the results from STM analysis applied to interviewees' tweets of provided topics aligning with the themes originating from the interviewees' responses. That the stated use of Twitter by the interviewees is consistent with their actual tweeting behaviour is a major theoretical finding. The validity of data collected from interviews can be criticised as it is based on a single time and place; however, the analysis of the Twitter data showed that their stated intentions in using Twitter and their actual tweets are consistent in nature (Rodriguez and Svensson, 2019) and this form of analysis can provide a pathway to contextualise the social media messages posted by the users.

\subsection{Managerial implications}

This research provides some pertinent managerial implications for the use of Twitter regarding innovation in business markets, by illustrating how social media platforms, such as Twitter, could be used as a source of information and for the exchange of high quality, relevant and current information as part of a firm's innovation process (D'Andrea et al., 2019). As an egalitarian platform, Twitter enabled interviewees to engage in conversations with customers and peers to support the development of product and service innovations. Twitter is a channel that allows SMEs to interact with or collaborate with firms of all sizes and provides opportunities for individual to engage with more senior opinion leaders and individuals that may not be able to access otherwise. These online interactions across companies around common topics create online communities of interest that can lead to greater brand engagement (D’Andrea et al., 2019; Yavuz and Toker, 2014).

The valuable use of STM to analyse tweets provides a strong case for enterprises and managers to include topic modelling analyses as part of social media analytics (Lee, 2018). Topic identification from users' Twitter posts can be utilised for topic-related event detection (Cui et al., 2016), enabling the user to target specific events. By using topic modelling to identify online conversation themes, events and others' achievements, individuals and firms can participate in these conversations in a congruent tone, thus improving their level of engagement and interaction (Valos et al., 2016). The topic models created in this research provide a lexicon of frequently used words around innovation, crowdsourcing, gathering ideas and social media marketing that could be used to source and engage in conversations around these topics. While engaging in online customer conversations has received attention 
in B2C markets (Zanini et al., 2019), this research found that conversations and connections around topics could also be beneficial in building B2B relationships.

The interviewees considered that Twitter should not be used for direct marketing of products and services, but for informing and engaging customers and peers in their network on wider topics (Swani et al., 2014; Hänninen and Karjaluoto, 2017). The research found that Twitter was effective for promoting events, for recognition of others in the network and for building the brand of individuals and companies. The reciprocation of interests and ideas created connections with others on Twitter that could lead to new business opportunities.

Finally, very few of the companies interviewed had any formal framework for the measurement of their return on investment (ROI) for Twitter. They considered it to be 'worthwhile and important to be there' but lacked clearly defined objectives for their participation or the expenditure of time and resources (Inakova et al., 2019). To effectively manage and measure their use of Twitter, it is suggested that a firm's social media activity be merged into a Customer Relationship Management system (Ramadan et al., 2018) and guidelines be established that facilitate the care and engagement of their Twitter community to ensure their ongoing participation (Chesbrough, 2011).

\section{Conclusion}

This research provided evidence of how Twitter is for B2B marketing (Sashittal and Jassawalla, 2019) and demonstrated that Twitter can be a tool for crowdsourcing, knowledge sharing and creating innovation in B2B markets, thereby answering some of the questions raised by Salo (2017), Salo et al. (2013) and Karjaluoto et al. (2015). The results are supported by the qualitative data from the interviews and verified by the STM analysis of the tweets. The research findings support previous research analysing corporate communications where it was found that Twitter posts focussed around customer feedback and marketing content (promotions, announcements, etc.) (He et al., 2013).

Further investigation is required on the formalisation of social media strategies by firms and measurement of the ROI of their social media marketing efforts (Inakova et al., 2019; Salo, 2017). Text analysis methods like sentiment analysis, STM and social network analysis can also be applied to generate further insights into the impact of online platforms in the B2B context. The globalised environment will continue to fuel the growth of phenomena such as start-ups, crowdsourcing platforms and open source innovation through online platforms such as Twitter, and ongoing research is required to assist companies to navigate this changing landscape.

\section{Notes}

1. This definition is not absolute and varies in different countries based on their categorisation. This definition was used for convenience and to account for small companies.

2. There are some studies which support the use of Google Translate API or similar machine translation tools for text mining (Lucas et al., 2015; de Vries et al., 2018).

3. Two topics are connected to each other if their correlation is greater than 0.05 . This can be tested for different values of the correlations. A low level of correlation is chosen to group topics, which are similar to even a low degree.

\section{References}

Amyx, D., Bhuian, S., and Shows, D. (2016), "Customer-salespeople relationship: influence of salespeople entrepreneurial behaviours", Marketing Intelligence \& Planning, Vol. 34 No. 5, pp. 586-604. 
MIP

38,5

598

Andzulis, J.M., Panagopoulos, N.G. and Rapp, A. (2012), "A review of social media and implications for the sales process", Journal of Personal Selling and Sales Management, Vol. 32 No. 3, pp. 305-316.

Blei, D.M., Ng, A.Y. and Jordan, M.I. (2003), "Latent dirichlet allocation”, Journal of Machine Learning Research, Vol. 3 January, pp. 993-1022.

Bower, J.L. and Christensen, C.M. (1995), "Disruptive technologies”, Harvard Business Review, Vol. 73 No. 1, pp. 43-53.

Chen, H., Chiang, R.H.L. and Storey, V.C. (2012), "Business intelligence and analytics: from big data to big impact", MIS Quarterly, Vol. 36 No. 4, pp. 1165-1188.

Chesbrough, H.W. (2003), Open Innovation, Harvard Business School Press, Boston, MA.

Chesbrough, H.W. (2011), "Foreword", in Sloane, S. (Ed.), A Guide to Open Innovation and Crowdsourcing, Kogan Page, Philadelphia, PA, pp. xvii-xix.

Cui, L., Zhang, X., Zhou, X. and Salim, F. (2016), Topical Event Detection on Twitter, Springer International Publishing, Cham, pp. 257-268.

Curran, K., O'Hara, K. and O'Brien, S. (2011), "The role of Twitter in the world of business", International Journal of Business Data Communications and Networking, Vol. 7 No. 3, pp. 1-15.

D’Andrea, F., Rigon, F., Almeida, A., Filomena, B. and Slongo, L. (2019), "Co-creation: a b2c and b2b comparative analysis”, Marketing Intelligence \& Planning, Vol. 37 No. 6, pp. 674-688.

Daghfous, A., Jeremy Ashill, N. and Roger Rod, M. (2013), “Transferring knowledge for organisational customers by knowledge intensive business service marketing firms", Marketing Intelligence \& Planning, Vol. 31 No. 4, pp. 421-442.

de Vries, E., Schoonvelde, M. and Schumacher, G. (2018), "No longer lost in translation: evidence that Google translate works for comparative bag-of-words text applications", Political Analysis, Vol. 26 No. 4, pp. 417-430.

Dobele, A., Steel, M. and Cooper, T. (2015), "Sailing the seven C's of Blogblog marketing: understanding social media and business impact. Marketing: understanding Social Media and Business Impact", Marketing Intelligence \& Planning, Vol. 33 No. 7, pp. 1087-1102.

Edosomwan, S., Kalangot Prakasan, S., Kouame, D., Watson, J. and Seymour, T. (2011), "The history of social media and its impact on business", The Journal of Applied Management and Entrepreneurship, Vol. 16 No. 3, pp. 79-91.

Estellés-Arolas, E. and González-Ladrón-de-Guevara, F. (2012), "Towards an integrated crowdsourcing definition”, Journal of Information Science, Vol. 38 No. 2, pp. 189-200.

Floresa, R.L., Negny, S., Belaud, J.P. and Le Lann, J.-M. (2015), “Collective intelligence to solve creative problems in conceptual design phase”, Procedia Engineering, Vol. 131, pp. 850-860.

Fontana, A. and Frey, J.H. (2005), "The interview: from structured questions to negotiated test", in Denzin, N.K. and Lincoln, Y.S. (Eds), The Sage Handbook of Qualitative Research, 3rd ed., Sage Publications, Thousand Oaks, CA, pp. 695-727.

Hänninen, N. and Karjaluoto, H. (2017), "The effect of marketing communication on business relationship loyalty”, Marketing Intelligence \& Planning, Vol. 35 No. 4, pp. 458-472.

He, W. and Wang, F.-K. (2016), "A process-based framework of using social media to support innovation process", Information Technology and Management, Vol. 17 No. 3, pp. 263-277.

He, W., Zha, S. and Li, L. (2013), "Social media competitive analysis and text mining: a case study in the pizza industry", International Journal of Information Management, Vol. 33 No. 3, pp. 464-472.

Huotari, L., Ulkuniemi, P., Saraniemi, S. and Malaska, M. (2015), "Analysis of content creation in social media by B2B companies", Journal of Business and Industrial Marketing, Vol. 30 No. 6, pp. 761-770.

Iankova, S., Davies, I., Archer-Brown, C., Marder, B. and Yau, A. (2019), "A comparison of social media marketing between B2b, B2c and mixed business models", Industrial Marketing Management, Vol. 81, pp. 169-179. 
Jussila, J.J., Kärkkäinen, H. and Aramo-Immonen, H. (2014), "Social media utilization in business-tobusiness relationships of technology industry firms", Computers in Human Behavior, Vol. 30, pp. 606-613.

Kaplan, A.M. and Haenlein, M. (2010), "Users of the world, unite! the challenges and opportunities of social media”, Business Horizons, Vol. 53, pp. 59-68.

Karjaluoto, H., Mustonen, N. and Ulkuniemi, P. (2015), "The role of digital channels in industrial marketing communications", Journal of Business and Industrial Marketing, Vol. 30 No. 6, pp. 703-710.

Keinänen, H. and Kuivalainen, O. (2015), "Antecedents of social media B2b use in industrial marketing context: customers' view”, Journal of Business and Industrial Marketing, Vol. 30 No. 6, pp. 711-722.

Khedher, M. (2014), "Personal branding phenomenon", International Journal of Information, Business and Management, Vol. 6 No. 2, pp. 29-40.

Lee, I. (2018), "Social media analytics for enterprises: typology, methods and processes", Business Horizons, Vol. 61 No. 2, pp. 199-210.

Leek, S., Houghton, D. and Canning, L. (2019), "Twitter and behavioral engagement in the healthcare sector: an examination of product and service companies", Industrial Marketing Management, Vol. 81, pp. 115-129.

Leonardi P.M. (2014), "Social media, knowledge sharing, and innovation: toward a theory of communication visibility", Information Systems Research, Vol. 25 No. 4, pp. 796-816.

Leonardi, P.M., Huysman, M. and Steinfield, C. (2013), "Enterprise social media: definition, history, and prospects for the study of social technologies in organizations", Journal of Computer-Mediated Communication, Vol. 19, pp. 1-19.

Lucas, C., Nielsen, R.A., Roberts, M.E., Stewart, B.M., Storer, A. and Tingley, D. (2015), "Computerassisted text analysis for comparative politics", Political Analysis, Vol. 23 No. 2, pp. 254-277.

Lusch, R.F. and Nambisan, S. (2015), "Service innovation: a service-dominant logic perspective", MIS Quarterly, Vol. 39 No. 1, pp. 155-175.

Mehmet, M.I. and Clarke, R.J. (2016), "B2B social media semantics: analysing multimodal online meanings in marketing conversations", Industrial Marketing Management, Vol. 54, pp. 92-106.

Mejtoft, T. (2014), "Building relationships for survival: coping media industry dynamics", in Woodside, A., Marshall, R. and Pattinson, H. (Eds), Field Guide to Case Study Research in Business-to-Business Marketing and Purchasing. Advances in business marketing and purchasing, Vol. 21, Emerald Group Publishing Limited, Bingley, UK, pp. 39-59.

Morgan, R.M. and Hunt, S.D. (1994), "The commitment-trust theory of relationship marketing”, Journal of Marketing, Vol. 58 No. 3, pp. 20-38.

Ngai, E.W.T., Tao, S.S.C. and Moon, K.K.L. (2015), "Social media research: theories, constructs, and conceptual frameworks", International Journal of Information Management, Vol. 35 No. 1, p. 33-44.

Pérez-González, D., Trigueros-Preciado, S. and Popa, S. (2017), "Social media technologies' use for the competitive information and knowledge sharing, and its effects on industrial SMEs' innovation", Information Systems Management, Vol. 34 No. 3, pp. 291-301.

Poon, P., Albaum, G. and Shiu-Fai Chan, P. (2012), "Managing trust in direct selling relationships", Marketing Intelligence \& Planning, Vol. 30 No. 5, pp. 588-603.

Quinton, S. and Wilson, D. (2016), "Tensions and ties in social media networks: towards a model of understanding business relationship development and business performance enhancement through the use of linkedin”, Industrial Marketing Management, Vol. 54, p. 15-24.

Ramadan, Z., Farah, M. and Dukenjian, A. (2018), "Typology of social media followers: the case of luxury brands", Marketing Intelligence \& Planning, Vol. 36 No. 5, pp. 558-571. 
MIP

38,5

600

Roberts, M.E., Stewart, B.M. and Airoldi, E.M. (2016), "A model of text for experimentation in the social sciences”, Journal of the American Statistical Association, Vol. 111 No. 515, pp. 988-1003, doi: 10.1080/01621459.2016.1141684.

Roberts, M.E., Stewart, B.M. and Tingley, D. (2014a), "stm: R package for structural topic models", Journal of Statistical Software, Vol. 10 No. 2, pp. 1-40.

Roberts, M.E., Stewart, B.M. and Tingley, D. (2014b), Navigating the Local Modes of Big Data: The Case of Topic Models, Cambridge University Press, New York.

Roberts, M.E., Stewart, B.M., Tingley, D., Lucas, C., Leder-Luis, J., Gadarian, S.K., Albertson, B. and Rand, D.G. (2014), "Structural topic models for open-ended survey responses", American Journal of Political Science, Vol. 58, pp. 1064-1082, doi: 10.1111/ajps.12103.

Rodriguez, R. and Svensson, G. (2019), "Time orientation in complex b2b service relationships", Marketing Intelligence \& Planning, Vol. 37 No. 4, pp. 451-464.

Salo, J. (2017), "Social media research in the industrial marketing field: review of literature and future research directions", Industrial Marketing Management, Vol. 66, pp. 115-129.

Salo, J., Lehtimäki, M., Simula, H. and Mäntymäki, M. (2013), "Social media marketing in the scandinavian industrial markets", International Journal of Entrepreneurial Behavior \& Research, Vol. 9 No. 4, pp. 16-32.

Sapsed, J. and Tschang, F.T. (2014), "Art is long, innovation is short: lessons from the Renaissance and the digital age", Technological Forecasting and Social Change, Vol. 83, pp. 127-141.

Sashittal, H. and Jassawalla, A. (2019), "Brand entification as a post-anthropomorphic attribution among twitter-using millennials", Marketing Intelligence \& Planning, Vol. 37 No. 7, pp. 741-753.

Schumpeter, J.A. (1934), The Theory of Economic Development, Harvard University Press, New Brunswick, NJ.

Scupola, A. and Nicolajsen, H. (2013), "Using social media for service innovation: challenges and pitfalls", International Journal of E-Business Research, Vol. 9 No. 3, pp. 27-37.

Shao, W., Jones, R.G. and Grace, D. (2015), "Brandscapes: contrasting corporate-generated versus consumer-generated media in the creation of brand meaning", Marketing Intelligence \& Planning, Vol. 33 No. 3, pp. 414-443.

Simula, H. and Ahola, T. (2014), "A network perspective on idea and innovation crowdsourcing in industrial firms", Industrial Marketing Management, Vol. 43, pp. 400-408.

Simula, H., Töllinen, A. and Karjaluoto, H. (2013), "Crowdsourcing in the social media era: a case study of industrial marketers", Journal of Marketing Development and Competitiveness, Vol. 7 No. 2, pp. 122-137.

Stake, R.E. (2005), "Qualitative case studies", in Denzin, N.K. and Lincoln, Y.S. (Eds), The Sage Handbook of Qualitative Research, 3rd ed., Sage Publications, Thousand Oaks, CA, pp. 695-727.

Sundbo, J., (1997), "Management of innovation in services", The Service Industries Journal, Vol. 17 No. 3, pp. 432-455.

Swani, K., Brown, B.P. and Milne, G.R. (2014), "Should tweets differ for B2B and B2C? An analysis of Fortune 500 companies' Twitter communications”, Industrial Marketing Management, Vol. 43 No. 5, pp. 873-881.

Tarnovskaya, V. and Biedenbach, G. (2018), "Corporate rebranding failure and brand meanings in the digital environment”, Marketing Intelligence \& Planning, Vol. 36 No. 4, pp. 455-469.

Tsimonis, G. and Dimitriadis, S. (2014), "Brand strategies in social media", Marketing Intelligence \& Planning, Vol. 32 No. 3, pp. 328-344.

Valos, M.J., Habibi, F.H., Casidy, R., Driesener, C.B. and Maplestone, V.L. (2016), "Exploring the integration of social media within integrated marketing communication frameworks: perspectives of services marketers", Marketing Intelligence \& Planning, Vol. 34 No. 1, pp. 19-40. 
Venkatesh, V., Thong, J.Y. and Xu, X. (2016), "Unified theory of acceptance and use of technology: a synthesis and the road ahead", Journal of the Association for Information Systems, Vol. 17 No. 5, pp. 328-376.

Use of Twitter in business

von Hippel, E. (1986), "Lead users: a source of novel product concepts", Management Science, Vol. 32 No. 7, pp. 791-805.

Wang, Y., Rod, M., Ji, S. and Deng, Q. (2017), "Social media capability in B2b marketing: toward a definition and a research model", The Journal of Business and Industrial Marketing, Vol. 32 No. 8, pp. 1125-1135.

Yavuz, R. and Toker, A. (2014), "Location sharing on social networks: implications for marketing", Marketing Intelligence \& Planning, Vol. 32 No. 5, pp. 567-585.

Zameer, H., Wang, Y. and Yasmeen, H. (2019), "Transformation of firm innovation activities into brand effect", Marketing Intelligence \& Planning, Vol. 37 No. 2, pp. 226-240.

Zanini, M., Lima, V., Migueles, C., Reis, I., Carbone, D. and Lourenco, C. (2019), "Soccer and twitter: virtual brand community engagement practices", Marketing Intelligence \& Planning, Vol. 37 No. 7, pp. 791-805.

\section{Corresponding author}

Helen Cripps can be contacted at: h.cripps@ecu.edu.au

For instructions on how to order reprints of this article, please visit our website:

www.emeraldgrouppublishing.com/licensing/reprints.htm

Or contact us for further details: permissions@emeraldinsight.com 